\title{
IDENTIFIKASI KEMATANGAN BUAH TOMAT BERDASARKAN WARNA MENGGUNAKAN METODE JARINGAN SYARAF TIRUAN (JST)
}

\author{
Sella Kusumaningtyas ${ }^{1}$, Rosa Andrie Asmara ${ }^{2}$ \\ Program Studi Teknik Informatika, Jurusan Teknologi Informasi, Politeknik Negeri Malang \\ 1sellakusumaa@gmail.com
}

\begin{abstract}
Abstrak
Proses pemilihan produk hasil pertanian dan perkebunan umumnya sangat bergantung pada presepsi manusia terhadap komposisi warna yang dimiliki citra yaitu buah-buahan. Cara manual dilakukan berdasarkan pengamatan visual secara langsung pada buah yang akan diklasifikasi. Identifikasi dengan cara ini memiliki beberapa kelemahan diantaranya adalah waktu yang dibutuhkan relatif lama serta menghasilkan produk yang beragam karena adanya keterbatasan visual manusia, tingkat kelelahan dan perbedaan persepsi tentang mutu buah.

Perkembangan ilmu pengetahuan dan teknologi pengolahan citra digital memungkinkan untuk memilah produk pertanian dan perkebunan tersebut secara otomatis dengan bantuan aplikasi pengolahan citra. Identifikasi kematangan buah tomat ini menerapkan metode pembelajaran Perceptron. Pendukung identifikasi menggunakan bantuan media webcam sebagai pengambilan gambar tomat yang dibuat histogram warnanya kemudian diidentifikasi menggunakan jaringan syaraf tiruan agar komputer dapat memperoleh informasi citra dan dapat mengetahui jenis kematangan buah tersebut. Tingkat keberhasilan identifikasi kematangan buah tomat yang didapatkan menggunakan metode pembelajaran perceptron dengan tingkat keberhasilan 43,33\%. Dari hasil identifikasi yang diperoleh menghasilkan 3 output yaitu Mentah 10\%, Setengah Matang 6,66\%, dan Matang $26,66 \%$.
\end{abstract}

Kata kunci : Tomat, Histogram, Jaringan Syaraf Tiruan, Perceptron.

\section{PENDAHULUAN}

Industri pengolahan hasil pertanian dan perkebunan sangat berkembang pesat. Salah satu tahap dalam proses pengolahan hasil perkebunan adalah pemilihan produk berdasarkan kualitasnya (misalnya tingkat kematangan buah). Proses pemilihan produk hasil pertanian dan perkebunan umumnya sangat bergantung pada presepsi manusia terhadap komposisi warna yang dimiliki citra (buahbuahan). Cara manual dilakukan berdasarkan pengamatan visual secara langsung pada buah yang akan diklasifikasi. Kelemahan klasifikasi buah secara manual sangat dipengaruhi oleh subjektifitas petugas penyortiran sehingga dalam kondisi tertentu tidak spesifik proses pengklasifikasikannya. Identifikasi dengan cara ini memiliki beberapa kelemahan diantaranya adalah waktu yang dibutuhkan relatif lama serta menghasilkan produk yang beragam karena adanya keterbatasan visual manusia, tingkat kelelahan dan perbedaan persepsi tentang mutu buah. Perkembangan ilmu pengetahuan dan teknologi pengolahan citra digital memungkinkan untuk memilah produk pertanian dan perkebunan tersebut secara otomatis dengan bantuan aplikasi pengolah citra.

Berdasarkan uraian diatas, maka perlu dibangun sebuah sistem "Identifikasi Kematangan Buah Tomat Berdasarkan Warna Menggunakan Metode Jaringan
Syaraf Tiruan (JST)". Sehingga dapat memudahkan dan meningkatkan kinerja para petugas penyortiran dalam memilih tingkat kematangan buah.

\section{LANDASAN TEORI}

\subsection{Tomat}

Tomat (Lycopersicum esculentum) adalah tumbuhan dari keluarga Solanacease, tumbuhan asli Amerika Tengah dan Selatan, dari Meksiko sampai Peru. Kata "tomat" berasal dari kata dalam bahasa Nauhat, dimana tomat merupakan keluarga dekat dari kentang. (Achmad Sabiro dkk, 2012)

\subsection{Pengolahan Citra}

Pengolahan citra adalah pemrosesan citra atau image processing, khususnya dengan menggunakan komputer menjadi citra yang kualitasnya lebih baik. Dengan kata lain pengolahan citra adalah kegiatan memperbaiki kualitas citra agar mudah diinterprestasi oleh manusia atau mesin. (Igief Rizekiya Suprayogi, 2010)

\subsection{Citra Digital}

Citra digital adalah representasi, kemiripan, atau imitasi dari suatu objek. Citra sebagai keluaran suatu sistem perekaman data dapat bersifat optik berupa foto, bersifat analog berupa sinyal-sinyal video seperti gambar pada monitor televisi, atau bersifat 
digital yang dapat langsung disimpan pada suatu media penyimpanan. (Sutoyo, 2009).

\subsection{Histogram Warna}

Histogram Warna atau color histogram adalah representasi distribusi warna dalam sebuah gambar yang didapatkan dengan menghitung jumlah pixel dari setiap bagian range warna, secara tipikal dalam dua dimensi atau tiga dimensi. Dalam pembuatan histogram, nilai RGB mempunyai range dari 0 sampai 255 akan punya kombinasi warna sebesar 16777216 (didapatkan dari : 255 × 255 x 255).

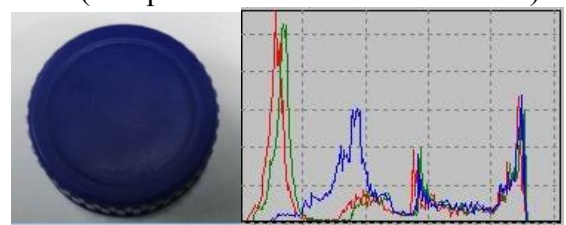

Gambar 1. Gambar Berwarna dan histogramnya

\subsection{Jaringan Syaraf Tiruan (JST)}

Jaringan Syaraf Tiruan (JST) merupakan salah satu representasi buatan dari otak manusia yang selalu mencoba untuk mensimulasikan proses pembelajaran pada otak manusia tersebut. Istilah buatan digunakan karena jaringan syaraf ini diimplementasikan dengan menggunakan program komputer yang mampu menyelesaikan sejumlah proses perhitungan selama proses pembelajaran.

\subsection{Perceptron}

Perceptron biasanya digunakan untuk mengklasifikasikan suatu tipe pola tertentu yang sering dikenal dengan pemisahan secara linear. Algoritma yang digunakanakan mengatur parameterparameter bebasnya melalui proses pembelajaran. Pada Tahun 1958, Rosenblatt mengembangkan konsep dasar tentang perception untuk klasifikasi pola.

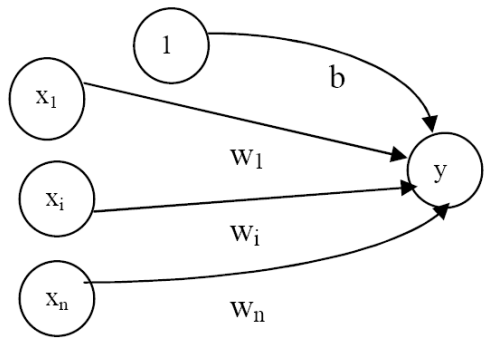

Gambar 2. Arsitektur Perceptron Sederhana

\section{METODOLOGI PENELITIAN}

Metode pembuatan perangkat lunak ini adalah dengan menggunakan metode Waterfall. Menurut Sommerville (2011:29) Waterfall model mengambil kegiatan proses dasar spesifikasi, pengembangan, validasi, dan evolusi dan mewakili kegiatan tersebut sebagai fase terpisah seperti spesifikasi persyaratan, perancangan perangkat lunak, implementasi, pengujian dan sebagainya. Adapun tahap dalam metode waterfall ini adalah sebagai berikut:

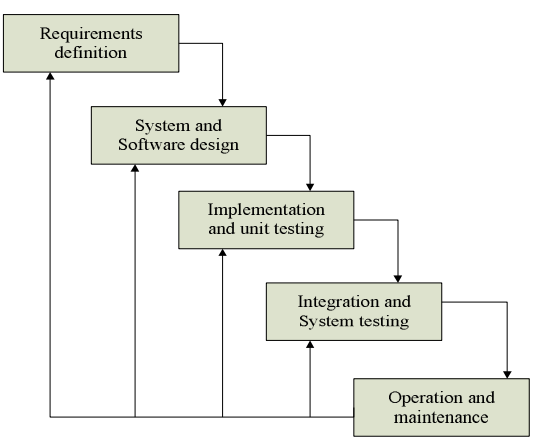

Gambar 3. Metode Waterfall

\section{ANALISIS DAN PERANCANGAN}

\subsection{Analisis Sistem}

Analisis sistem merupakan suatu penjabaran mengenai komponen-komponen penyusun sistem dalam penelitian ini baik perangkat lunak maupun perangkat keras. Serta gambaran umum sistem yang akan berjalan.

Fitur yang disediakan dalam aplikasi ini adalah hanya identifikasi kematangan buah dengan informasi nilai warna RGB (Red-Green-Blue) menggunakan metode pembelajaran perceptron sebagai klasifikasinya.

\subsection{Perancangan Sistem}

Pada perancangan proses untuk aplikasi identifikasi kematangan buah tomat berdasarkan warna menggunakan metode Jaringan Syaraf Tiruan (JST) akan disajikan ke dalam bentuk Flowchart dan proses Identifikasi Buah Tomat menggunakan single perceptron.

Berikut ini adalah rancangan proses identifikasi kematangan buah menggunakan metode pembelajaran single perceptron.

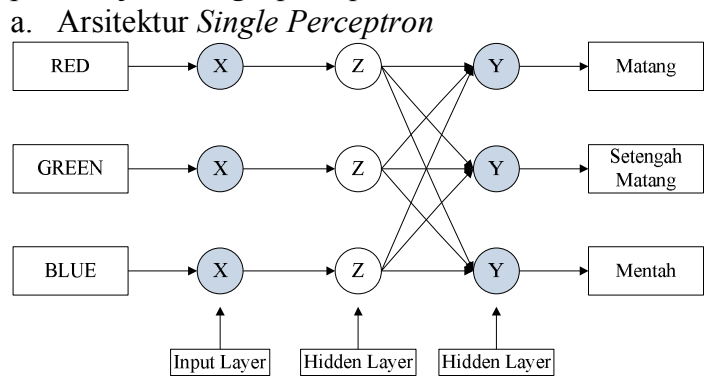

Gambar 4. Proses perceptron

Perancangan single perceptron ini menggunakan 3 input, 3 node hidden layer dan 3 unit output.

b. Rancangan Pembelajaran (training) perceptron :

Citra $=>$ histogram warna $=>$ pola $=>$ training $=>$ bobot

c. Rancangan proses identifikasi perceptron :

Citra $=>$ histogram warna $=>$ pola $=>$ identifikasi (dari bobot) 


\section{IMPLEMENTASI}

Dalam Identifikasi terdapat 2 proses yaitu segmentasi dan klasifikasi menggunakan metode pembelajaran perceptron. Dimana proses segmentasi akan menampilkan nilai Max RGB, Mean dan ratarata pada gambar. Kemudian akan menampilkan juga grafik histogram yang terbagi atas komponen warna merah, hijau dan biru. Sedangkan pada proses Identifikasi menggunakan metode pembelajaran perceptron akan menampilkan hasil dan hasil proses perceptron. Berikut adalah hasil dari identifikasi tomat matang.

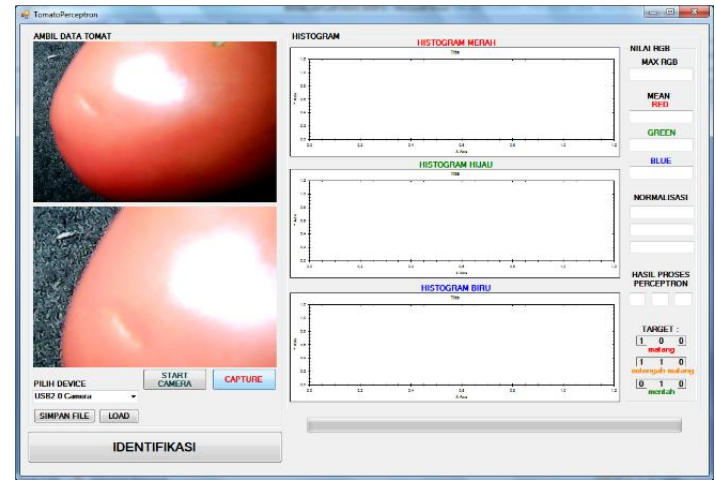

Gambar 5. Halaman Utama

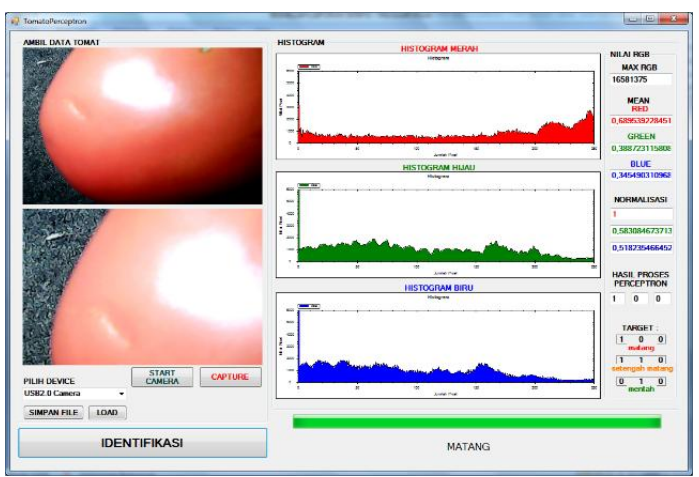

Gambar 6. Proses identifikasi buah tomat

\section{PENGUJIAN DAN PEMBAHASAN}

Pada pengujian untuk aplikasi identifikasi kematangan buah tomat yaitu menggunakan pengujian Unit dan pengujian akurasi. Pengujian Unit ini dilakukan dengan cara menjalankan aplikasi secara detail pada setiap konten yang ada, yang bertujuan untuk mengetahui fitur mana yang sudah berfungsi dengan baik, dan fitur mana yang harus diperbaiki karena tidak sesuai dengan fungsinya. Berikut merupakan hasil uji coba yang telah dilakukan untuk mengidentifikasi tomat mentah, setengah matang, dan matang.

\subsection{Pengujian Unit}

Pengujian Unit ini dilakukan dengan cara menjalankan aplikasi secara detail pada setiap konten yang ada, yang bertujuan untuk mengetahui fitur mana yang sudah berfungsi dengan baik, dan fitur mana yang harus diperbaiki karena tidak sesuai dengan fungsinya. Berikut ini adalah contoh pengujian pada 3 kategori tomat.

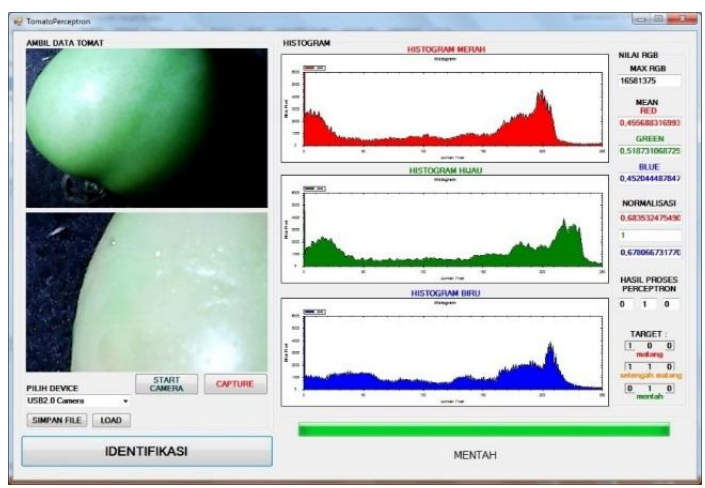

Gambar 7. Identifikasi Buah Tomat Warna Hijau

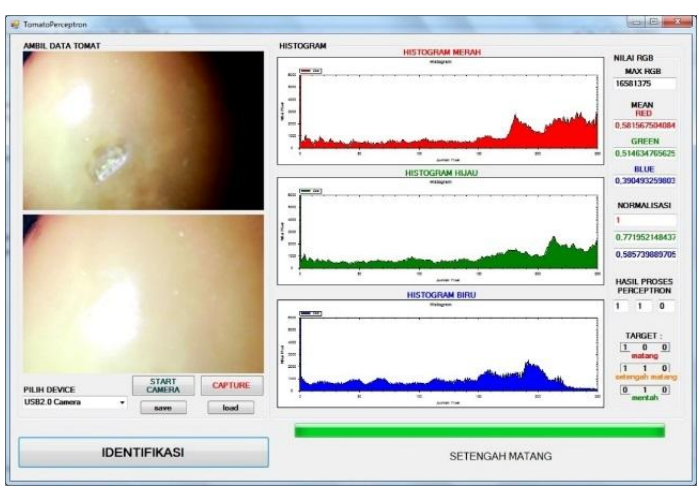

Gambar 7. Identifikasi Buah Tomat Warna Campur (Merah dan Kuning)

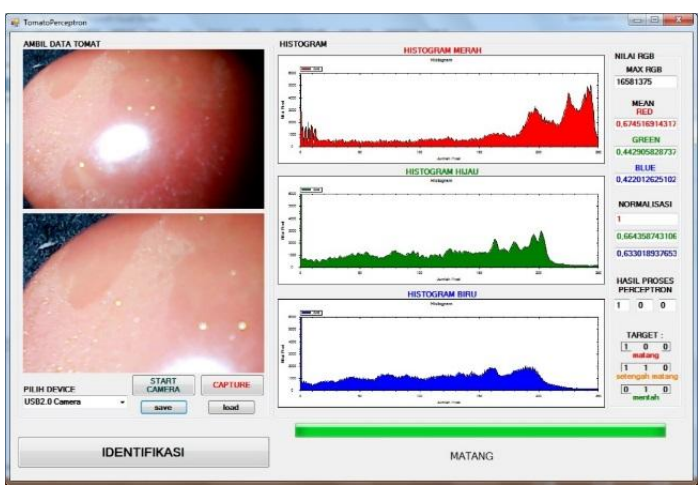

Gambar 8. Identifikasi Buah Tomat Warna Merah

\subsection{Pengujian Akurasi}

Akurasi Hasil Training perceptron melalui 70000 iterasi (epoch) dan dalam pengujian ini diperlukan sebanyak 30 sampel buah tomat yang terdiri dari tomat hijau, tomat campur (kombinasi kuning dan merah) dan tomat merah. Tingkat keakuratannya adalah dapat dilihat pada Tabel 1. 
Tabel 1. Pengujian Akurasi

\begin{tabular}{|c|c|c|c|c|}
\hline $\begin{array}{c}\text { Kategori } \\
\text { Tomat }\end{array}$ & $\begin{array}{c}\text { Jumlah } \\
\text { Sample }\end{array}$ & Sesuai & Error & $\begin{array}{c}\text { Tingkat } \\
\text { Akurasi }\end{array}$ \\
\hline Mentah & 10 & 3 & 7 & $\mathbf{1 0 \%}$ \\
\hline $\begin{array}{c}\text { Setengah } \\
\text { Matang }\end{array}$ & 10 & 2 & 8 & $\mathbf{6 , 6 6 \%}$ \\
\hline Matang & 10 & 8 & 2 & $\mathbf{2 6 , 6 6 \%}$ \\
\hline
\end{tabular}

Dari hasil identifikasi pada Tabel 1 didapatkan tingkat keberhasilan identifikasi kematangan buah tomat menggunakan metode pembelajaran perceptron. Untuk identifikasi buah tomat matang dan mentah lebih tinggi dibanding identifikasi buah yang setengah matang karena untuk pola histogram warna buah setengah matang tidak beraturan karena pengaruh pencahyaan saat pengambilan hasil uji. Dari keseluruhan data yaitu 30 buah data hasil pengujian dapat dirumuskan sebagai berikut :

$\frac{\text { Jumlah data identifikasi }}{\text { Jumlah pengambilan seluruh data }} \quad \times 100 \%$

Maka didapatkan tingkat akurasi sebagai berikut :

$13 \times 100 \%=43,33 \%$

$\overline{30}$

Tingkat keberhasilan identifikasi buah tomat secara keseluruhan adalah 43,33\%.

\section{Kesimpulan}

\subsection{Kesimpulan}

Berdasarkan hasil dari penelitian yang dilakukan dapat diambil beberapa kesimpulan sebagai berikut :

1. Dalam identifikasi kematangan buah tomat menggunakan metode pembelajaran perceptron pada saat proses identifikasi satu proses hanya dapat menerima satu masukan (input) parameter warna (merah, hijau, biru).

2. Identifikasi kematangan buah tomat dengan mengimplementasikan algoritma perceptron memperoleh tingkat keberhasilan identifikasi sebesar $43,33 \%$.

3. Dari hasil identifikasi dengan menggunakan perceptron yang diperoleh yaitu menghasilkan 3 output Mentah sebesar 10\%, Setengah Matang sebesar 6,66\%, dan Matang sebesar 26,66\%.

4. Identifikasi kematangan buah tomat menggunakan metode perceptron paling banyak mendeteksi buah tomat masak dan mentah, bila dibandingkan dengan buah tomat setengah matang karena kurangnya pencahayaan dan minimnya spesifikasi kamera.

\subsection{Saran}

Saran yang ditujukan untuk pengembangan penelitian ini adalah :

1. Diharapkan dengan pengembangan aplikasi identifikasi kematangan buah tomat dapat menambah spesifikasi media webcam dan pencahayaan yang cukup baik.

2. Pada pengembangan aplikasi selanjutnya diharapkan dapat menggunakan jaringan multi layer sebagai klasifikasinya.

\section{Daftar Pustaka:}

Abdullah, Ade Gafar. Tanpa Tahun: Pengantar Kecerdasan Buatan Bab_IV_KCB. [Online] Tersedia :

http://file.upi.edu/Direktori/FPTK/JUR. PEND. TE KNIK_ELEKTRO/197211131999031 $\quad$ [17

Desember 2014]

Deswari, Dila dkk. (2014): Jurnal Informatika Identifikasi Kematangan Buah Tomat Menggunakan Metoda Backpropagation. Padang : Universitas Andalas, Politeknik Negeri Padang.

Iswahyudi, Catur. (2010): Jurnal Teknologi Prototype Aplikasi Untuk Mengukur Kematangan Buah Apel Berdasarkan Kemiripan Warna. Yogyakarta : Institut Sains \& Teknologi AKPRIND.

Pengantar Kecerdasan Buatan (AK045218)Jaringan Syaraf Tiruan.(2013) : [Online] Tersedia :

http://lecturer.eepisits.edu/ entin/Kecerdasan\%20Buatan/Buku/Bab \%208\%20Jaringan $\% 20$ Syaraf\%20Tiruan.pdf [10 Desember 2014]

Pujiyatna, Ardi. (2009): Jurnal Informatika Pengenalan Citra Objek Sederhana Dengan Jaringan Saraf Tiruan Metode Perceptron. Yogyakarta : Universitas Ahmad Dahlan.

Sabiro, Achmad dkk. (2013): Mengenal Lebih Jauh Tomat. [Online] Tersedia : http://www.scribd.com/doc/37846069/Maka lah-TOMAT [10 Desember 2014]

Suprayogi, Igif Rizekiya. (2010). Identifikasi Bentuk Kendaraan Dengan Menggunakan Jaringan Saraf Tiruan. Malang : Universitas Islam. 